\title{
An Improved Technique for the Preparation of Mounted or Unmounted Carbon/Epoxy Specimens
}

\author{
R.A. Edahl, Jr.* \\ * Metals and Thermal Structures Branch, NASA-Langley Research Center, MS188A, Hampton, VA \\ 23681-2199
}

As carbon/epoxy materials became more prevalent in the aerospace industry, microstructural analysis demanded specimen preparation techniques that led to better polished surfaces, achievable in a shorter time, and using fewer steps. The desire to use image analysis for material characterization also helped drive the goal for defect free surfaces.

At NASA-Langley (LaRC), carbon/epoxy specimens had been historically prepared in 1 inch diameter Bakelite mounts. Carbon/epoxy specimens that were $1 / 8$ to $1 / 4$ inch thick were not affected by the heat and pressure required for mounting in Bakelite, however thinner specimens were crushed during mounting. A two-part room temperature curing epoxy was chosen as an alternative but sometimes voids developed between the specimen and the mounting material. This was prevented by either heating the epoxy to 180 degrees $F$ to lower the viscosity of the epoxy or by using a vacuum impregnation apparatus. Both techniques helped facilitate flow and allowed the epoxy to penetrate crevices.

The conventional sequence used to prepare carbon/epoxy specimens at LaRC (Table 1) was to rough grind with 240 grit $\mathrm{SiC}$ paper followed by 320 and 600 grit fine grinding steps. Rough polishing used 6 micron diamond paste with a diamond extender on Texmet ${ }^{2}$ [1] cloth. Final polishing using colloidal silica on Mastertex ${ }^{\circledR}[1]$ cloth ended this conventional polishing sequence. The pressure applied on the specimens for all polishing steps was 5 psi. It was noticed that some specimens had deep scratches that could not be removed in later steps and that many fibers were chipped (Fig 1). The damage was first evident in specimens made up of 0 degree oriented fibers (fiber length normal to the plane of polish). Specimens that contained no fibers in the 0 degree orientation did not exhibit the deep scratches. After much experimentation it was realized that 600 grit $\mathrm{SiC}$ paper was causing the scratches in the 0 degree fibers and that colloidal silica was chipping the fibers. 600 grit SiC paper was eliminated, replaced by an 800 grit grinding step, and Masterpolish $\AA$ [1] on Microcloth ${ }^{\circledR}$ [1] replaced colloidal silica on Mastertex ${ }^{\circledR}$. The use of Microcloth ${ }^{\circledR}$, a cloth not as soft as Mastertex ${ }^{\circledR}$, reduced surface relief on the specimens. A modified polishing sequence that reduced the preparation time was developed: 240-320-400-800X2-6 micron diamond/Texmet $\AA$ Masterpolish $\AA /$ Microcloth $\AA$ (Table 2). The use of diamond lapping was evaluated to streamline the polishing sequence and retain high quality in finished samples. Replacing 6 micron diamond paste on a cloth with 3 micron diamond slurry on a textured copper lapping platen resulted in an extremely fine polish. Small amounts of chipping were still observed on some 0 degree fibers. With more experimentation a final polishing step using deagglomerated 0.3 micron alumina on Texmet ${ }^{\circledR}$ cloth was selected. Texmet ${ }^{\circledR}$ is a very hard cloth which limited the amount of surface relief on the specimen. The applied pressure was increased to $10 \mathrm{psi}$ for the final polishing step which was performed for 1 minute of which the final 15 seconds was a water purge of the cloth and workpiece. The improved polishing sequence (Table 3) was simplified down to three steps: 240 or 320-3 micron/copper lap-0.3 micron alumina/Texmet ${ }^{\circledR}$. For applications where a copper lapping platen 
was not available a modified sequence (Table 4) was developed: 240-320-400-800X2-6 micron diamond/Texmet ${ }^{\circledR}-0.3$ micron alumina/Texmet ${ }^{\circledR}$. Thus, what once was a not-so satisfactory procedure consisting of 5 steps and taking over 18 minutes was reduced to a sequence of 3 steps taking no more than 7 minutes and producing an excellent surface finish (Fig 2).

[1] Trademarks of Buehler Ltd. Lake Bluff, IL

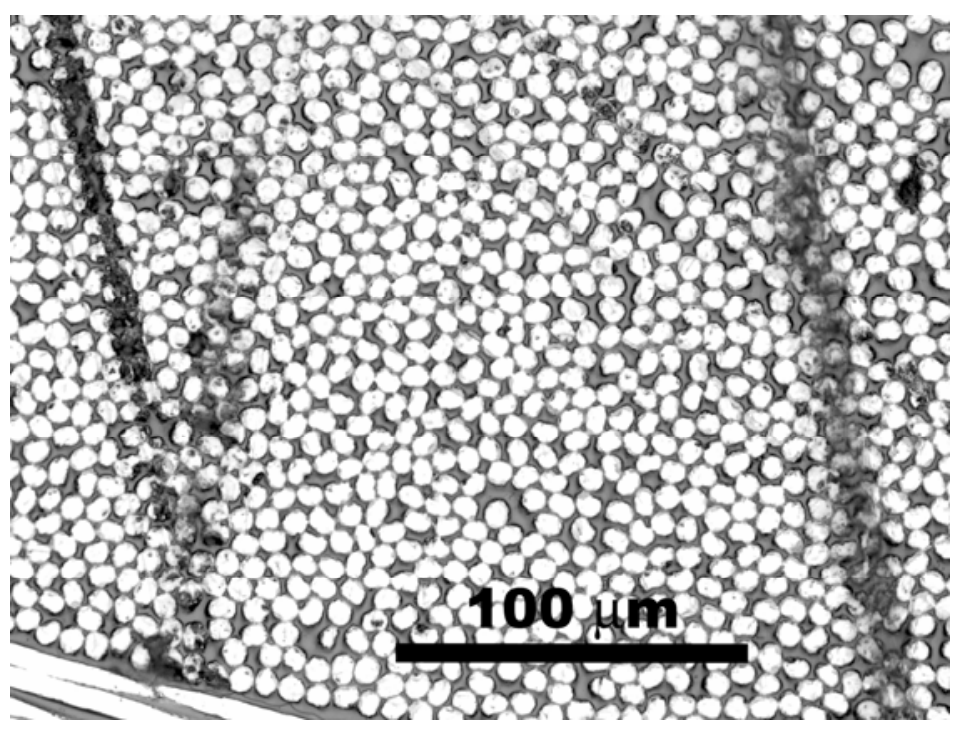

Fig 1. Prepared specimen using conventional polishing sequence

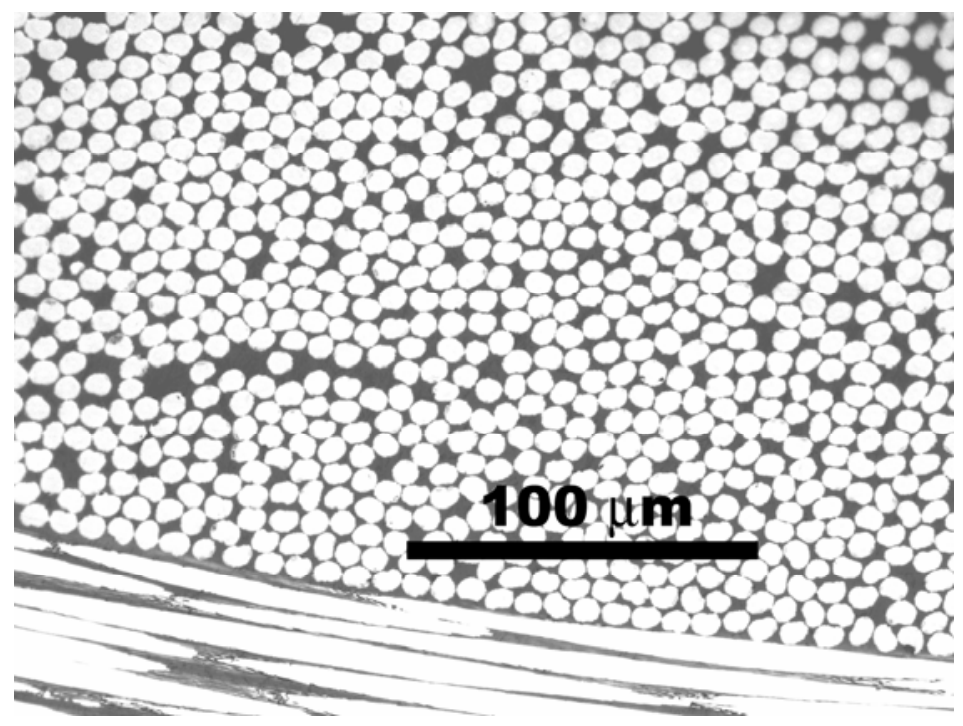

Fig 2. Prepared specimen using improved polishing sequence with copper lapping platen
TABLE 1. Conventional polishing sequence

\begin{tabular}{|l|l||l|}
\hline 1 & 240 grit $\mathrm{SiC}$ & $3 \mathrm{~min}$ \\
\hline 2 & 320 grit $\mathrm{SiC}$ & $3 \mathrm{~min}$ \\
\hline 3 & 600 grit $\mathrm{SiC}$ & $3 \mathrm{~min}$ \\
\hline 4 & $6 \mu$ diamond/Texmet $\AA$ & $6 \mathrm{~min}$ \\
\hline 5 & colloidal silica/Mastertex ${ }^{\circledR}$ & $3 \mathrm{~min}$ \\
\hline
\end{tabular}

TABLE 2. Modified polishing sequence

\begin{tabular}{|l|l|l|}
\hline 1 & 240 grit $\mathrm{SiC}$ & $1 \mathrm{~min}$ \\
\hline 2 & 320 grit $\mathrm{SiC}$ & $1 \mathrm{~min}$ \\
\hline 3 & 400 grit $\mathrm{SiC}$ & $1 \mathrm{~min}$ \\
\hline 4 & 800 grit $\mathrm{SiC}$ X 2 & $1 \mathrm{~min}$ \\
\hline 5 & $6 \mu$ diamond/Texmet $\AA$ & $3 \mathrm{~min}$ \\
\hline 6 & Masterpolish $\AA /$ Microcloth $\AA$ & $3 \mathrm{~min}$ \\
\hline
\end{tabular}

TABLE 3. Improved polishing sequence with copper platen

\begin{tabular}{|l|l|l|}
\hline 1 & 240 or 320 grit $\mathrm{SiC}$ & $1 \mathrm{~min}$ \\
\hline 2 & $3 \mu$ diamond/copper lap & $5 \mathrm{~min}$ \\
\hline 3 & $0.3 \mu$ alumina/Texmet $\mathbb{R}$ & $1 \mathrm{~min}$ \\
\hline
\end{tabular}

TABLE 4. Improved polishing sequence without copper platen

\begin{tabular}{|l|l|l|}
\hline 1 & 240 grit $\mathrm{SiC}$ & $1 \mathrm{~min}$ \\
\hline 2 & 320 grit $\mathrm{SiC}$ & $1 \mathrm{~min}$ \\
\hline 3 & 400 grit $\mathrm{SiC}$ & $1 \mathrm{~min}$ \\
\hline 4 & 800 grit $\mathrm{SiC} X 2$ & $1 \mathrm{~min}$ \\
\hline 5 & $6 \mu$ diamond/Texmet ${ }^{\circledR}$ & $3 \mathrm{~min}$ \\
\hline 6 & $0.3 \mu$ alumina/Texmet $\AA$ & $1 \mathrm{~min}$ \\
\hline
\end{tabular}

